\title{
Inspirational Education for College Students from Poor Family
}

\author{
Ying Liu \\ Chongqing three Gorges University \\ College of Economics and Management \\ Chongqing, China \\ jsliuying@163.com
}

\author{
Xiaohong Yang* \\ Southwest University \\ College of Horticulture and Landscape Architecture \\ Chongqing, China \\ yangxh2@swu.edu.cn \\ *Corresponding author
}

\begin{abstract}
With the rapid quantitative increase of college students at present, the absolute number of college students from poor family rises unceasingly. College students from poor family have drawn much social solicitude. Inspirational Education for college students from poor family is an important component in the students' work. The paper based on inspirational Education for college students from poor family and collegiate student work, explores effective ways and means of Inspirational Education for college students from poor family.
\end{abstract}

Keywords-colleges and universities; college students from poor family; collegiate student work; Inspirational Education

\section{INTRODUCTION}

Since the policy of expanding university enrollment was implemented in 1999, Chinese higher education has stepped into the stage of mass education from the elite one. More and more colleges and universities began to increase in charges, college students from poor family are also increase. The main causes for poor college students lie in the society, the families and the students themselves. Owing to the deficiency in ideological preparation and experience accumulation to adapt themselves to the multi culture, as well as the restriction of the family economic conditions, the poor college students result in their difficulty in adaptation. Owing to the deficiency in ideological preparation and experience accumulation to adapt themselves to the multi culture, as well as the restriction of the family economic conditions, the poor college students result in their difficulty in adaptation. These students have the following characteristics: for one thing they want to be succeeded by dint of hard work, for another the poverty of the family effects of their social activities and communication skills. So how to do inspirational education for college students from poor family is very important. Let the various economic aid to their spiritual support, Help them set up correct views, cultivate strong will and mental health, give full play to the subjective initiative, hard work, eventually become an all-round talent development, which is an urgent problem to be solved. Inspirational education for college students from poor family should not only reflected in economic aid, should start from the students' thought, pay attention to encouraging education family economic difficulties students, rich in content and Countermeasures of inspirational education, teach him to fish and teach him to fish, let them through their own efforts, to change their own destiny[1].

\section{PROBLEMS EXISTING IN THE MANAGEMENT OF COLLEGE STUDENTS FROM POOR FAMILY}

\section{A. The Difficult Subsidy}

We will improve the national financial aid system for students and increase financial aid for secondary vocational school and university students from poor families to ensure that everyone enjoys equal opportunity to receive education and that no child is denied schooling due to financial difficulties. But in the qualification cognizance, some students not from poor family with the poor students of the civil affairs departments and get economic benefits, and the real students from poor family due to various reasons (mainly psychological factors, such as inferiority) did not apply for poverty proof or not according to the rules of procedure for help. At the same time some students not from poor family do not know how to support oneself, And poverty phenomenon has always been.

\section{B. Learning}

For one thing the foundations of some students from poor family are weaker, and unable to adapt to living and learning in Colleges and universities, no learning method, led to the abandonment. for another some students from poor family has no interest in studies, Often play truant, and cause the academic waste. There are some students busy with all kinds of part-time and neglect their studies, they often go out part-time in the normal class time, but the study did not keep up, and finally had to drop out of school[2].

\section{Inspirational}

Due to the current university funding tend to focus only on economic poverty support, rather than on the spirit of poverty students guide. Because some students self-confidence, selfimprovement consciousness is weak, they do not want to ease the economic pressure through their own efforts, but hope in assistance and subsidies. Their self-restraint ability is poor, seriously hindered the ability to stand on their own culture. At the same time, because of the lack of life planning and target, they lack of ideal and goal. 


\section{Values}

Some students from poor family are from region economy, culture, education is relatively backward. Because of the environmental restriction affects the poor students correctly, objectively understand and treat himself, may form inferiority and autistic. Due to the self adjustment ability is weak, resulting in potential inhibition. But the current funding work relates to the students' psychological aspect, the lack of measurement system or better measures will guide students to establish the correct values [3].

\section{THE MAIN CONTENT OF INSPIRATIONAL EDUCATION FOR COLLEGE STUDENTS FROM POOR FAMILY}

\section{A. Foster Lofty Ideals, Build Self-Reliance Character}

College students from poor family are Mainly by laid-off workers, farmers, rural children of low income and single parent families. Lack of material life makes them desire for money too much. Society of "money worship" affects their outlook. There for we should guide students to a correct view of life, Foster lofty ideals, to understand the value of life lies in the creation and dedication, responsibility for the society. In view of this, we need to enhance our ideological and political work among college students to help them foster a healthy monetary outlook and to guide them to realize their perfection in ethics. Don't be a slave to money, really "do not fall Albatron ambition". As an ancient Chinese motto puts it, "as heaven keeps vigor through movement, a gentleman should unremittingly practice self-improvement." To "inspirational", the first "to". we should education them created a "hardworking, self-reliance" good quality and psychological confidence conceited or rash. In the college student system, We help the students understand the poor, at the same time cultivate their self-confidence, self-reliance, self-improvement character. At the same time, we should encourages, supports and gives guidance to the community service activities and part-time work= study program of the students, and will give them necessary help, which not only solve the difficulties, and self realization of the purpose of education. We sincerely hope that they'll aim high and to be ambitious and positive, to be a person who is never give up to achieve your career goals and ideals.

\section{B. Faithfulness and Thankfulness}

The problem of deficiency about the consciousness and quality of thanksgiving for students from poor families in colleges and universities has been become an important subject for university student tutors. Honesty is the moral bottom line of every college students the most basic, which not only reflects the personality of contemporary university students and the education, but also affects the development of students from poor families funding for the work of the national. It is very important in the college ideological and political education. Thanksgiving education is an important content of inspirational education, Not only help students with financial difficulties from inside an awareness and recognition of their endowments, helps them through their own practice. From the temple to Thanksgiving, Thanksgiving gratitude will be transformed into action to.

\section{Cultivate Healthy Psychology and Perfect Personality}

Because his family was poor, those students have different feelings of inferiority, and under the great pressure of study. Because the family economic distress, these students tend to have inward, inferiority, withdrawn and other psychological problems. So we should establish a mechanism for social psychological counseling to help people develop a sound and healthy personality. Some people can change the destiny through their own efforts, but most people can only fate. Care for them from the mental health level, to help them get rid of psychological distress caused by economic difficulties, The successful completion of their studies, is an important aspect of inspirational education of college students from poor families. And personality, namely we often say that the personality, refers to the sum and a personal psychological characteristics is relatively stable. A man's worth lies not in what he has but in what he is. Mental health plays an important role in the development of personality. A healthy psychology college students are often easier to be welcome. They are easy to create a harmonious environment, study in groups, cultivate and perfect all kinds of personality factors, such as self-confidence, hard work, perseverance, optimism, cooperation spirit etc[4].

\section{INSPIRATIONAL EDUCATION FOR COLLEGE STUDENTS FROM POOR FAMILY}

\section{A. Establish and Improve the Subsidy System in Colleges and Universities}

Colleges and universities must work to improve the aiding system, reinforce mental health education and offer psychological counseling services, lay stress on campus activities so that those needy students can walk out of their predicament and finish school smoothly. At present the national financial aid for college students with economic difficulties include loans, grants and scholarships inspirational. Our requirement was met to ensure a fair treatment for students receiving those funding, which is a prerequisite of inspirational education in Colleges and universities. In practice, we have lots of obstacles to surmount. As in the process of the degree of difficulty of the students, because the evaluation standard is not unified, strong subjectivity, this work is very difficult to guarantee absolute fairness. Do not rule out the possibility of overstating its degree of difficulty or resort to deceit students. Therefore, colleges and universities must establish and improve the subsidy system, Detailed identification of poverty standard, strengthen audit and supervision, to establish credibility files, put an end to resort to deceit behavior, ensure the smooth development of inspirational education in Colleges and universities.

\section{B. The Establishment of the Organization}

Classroom is the main position of inspirational education. Ideological and political theory course, college student occupation planning and employment guidance course, psychological health education course are the main courses to inspirational Education. Because of the family difficulties, most of the students from poor family are very cherish learning opportunities, and they are willing to accept the teacher's teaching. Teachers are expected to assess at a very high level 
here. Therefore, in order to enrich the content of these courses, the Three Outlooks education, education, education of honesty, gratitude education into the ideological and political theory in the classroom, to influence the economic difficulties students positive [5].

\section{The Rich Connotation of Inspirational Education}

To organize university student cadres' social practice is an important means of carrying out quality education and improving students' knowledge and skills as well as their creativity and practical abilities, and promoting school reform. Information literacy of the college student accomplishment needs to be taken exercise and checked in social practice. Social practice can help university student cadres able to selfsupporting and adapt to the social life. To organize university student cadres' social practice is an important means of carrying out quality education and improving students' knowledge and skills as well as their creativity and practical abilities, and promoting school reform. Information literacy of the college student accomplishment needs to be taken exercise and checked in social practice. Social practice can help university student cadres able to self-supporting and adapt to the social life.

\section{Strengthening Ideological and Political Education}

Ideological and political instructors are the main personnel to carry out the student work in Colleges and Universities. University instructors are backbone in students ideological and political work and play an important role in training talent. The career self-efficacy of college prefects influences the result of their work and the development of themselves. As a student leader and guide, they have extremely great ideological education responsibility. Student cadres in charge of student work, Party Secretary of the League branch secretary, instructors and students cadres, the level of their quality, directly affect Inspirational Education for college students from poor family.

We know the reasons that caused spirit poverty of poor college students through analyzing the aspects of economy, society, education and college students themselves. The external cause include the economic pressure from the college tuition and living expenditure ,the wrong understanding towards some social phenomena, the impact of both social value and social culture, and schools and family education. And there are two internal causes. One is that poor college students cannot face up to the poverty they are suffering, the other is their individual unhealthy psychological quality. The educational strategies for poor college students, healthy growth from the perspective of higher education. There are various channels to solve the spirit poverty of poor college students, which should be kept in mind that financial assistance is the premise, psychological tutor is the focal point, ideological education is the key, and widening the employment channels is the Principal way. In addition, to eradicate this problem, the joint effort from both society and family is indispensable [6].

\section{REFERENCES}

[1] Mei Hua, The study of problems and countermeasures on funding students fome poor families in colleges-Acase of jinggangshan university .2012

[2] Chen Chi-Hua, Analys on the humanistic care of the ideological and political education on college students with family financial difficulty.2012.

[3] Chen Wen, Chen Xin, Wang Guo-Ping, Liao Li, investigation and Analysis to the Mental Health Status of the Poverty College Students, China Journal of Health Psychology, vol.16,pp.631-633,June 2008.

[4] Zhang Xiao- Dong, Primary study in the Issue of Poor University Students, Journal of chinese youth politics academy ,vol.05,pp.5760,May 2006.

[5] Gao Wei, The study of family financial difficult students, problems and countermeasure of Chongqing universities.2005.

[6] Chen Xu-Wen, The Problem of Poor College Students. SPirit Povert yand Education Strategy-Taking the Western Braneh of Zhejiang University of Teehnology for ExamPle.2008. 